TI 2017-099/VIII

Tinbergen Institute Discussion Paper
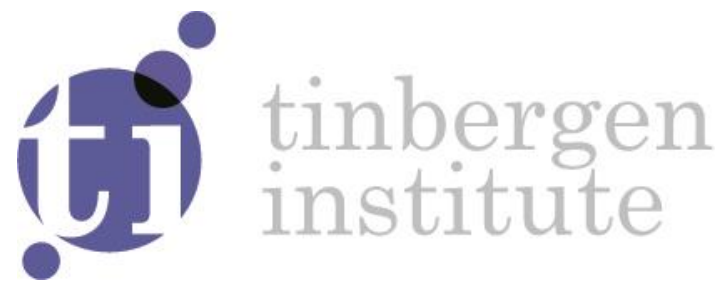

\title{
The total size of an airline and the quality of its flights
}

Joep van Montfort ${ }^{1}$

Vincent A.C. van den Berg ${ }^{2}$

${ }^{1}$ Department of Spatial Economics, Vrije Universiteit Amsterdam

${ }^{2}$ Department of Spatial Economics, Vrije Universiteit Amsterdam; Tinbergen Institute, The Netherlands 
Tinbergen Institute is the graduate school and research institute in economics of Erasmus University Rotterdam, the University of Amsterdam and VU University Amsterdam.

Contact: discussionpapers@tinbergen.nl

More TI discussion papers can be downloaded at http://www.tinbergen.nl

Tinbergen Institute has two locations:

Tinbergen Institute Amsterdam

Gustav Mahlerplein 117

1082 MS Amsterdam

The Netherlands

Tel.: + 31(0)205984580

Tinbergen Institute Rotterdam

Burg. Oudlaan 50

3062 PA Rotterdam

The Netherlands

Tel.: +31(0)10408 8900 


\title{
The total size of an airline and the quality of its flights
}

Version of 16 October 2017

\author{
Joep van Montfort ${ }^{\mathrm{a}} \&$ Vincent A.C. van den Berga,,,\# \\ a: Department of Spatial Economics, Vrije Universiteit Amsterdam, De Boelelaan 1105, 1081HV \\ Amsterdam, The Netherlands \\ *: Corresponding author: email: v.a.c.vanden.berg@vu.nl, tel: +31 205986049 \\ \#: Affiliated to the Tinbergen Institute, Gustav Mahlerplein 117, 1082 MS Amsterdam
}

\begin{abstract}
We examine the relationship between the total size of an airline and its service quality by analysing over 4.8 million domestic flights within the USA in 2016. The total size of an airline is measured by its total market share, total amount of assets or total number of fulltime equivalent employees. Delays are a widely used proxy for service quality and the most common category of airline customer complaints. Numerous regressions have been estimated using arrival delay time and whether a flight arrives on time as dependent variables. The regressors of main interest were the total airline size and the degree of competition on the route and airport. We control for weather, congestion, date, and characteristics of the airport, flight and airplane. The results suggest that the larger the total size of an airline, the smaller its average delay time and delay occurrence. Hence, larger airlines seem to offer a higher quality in terms of delays. We also find that an origin airport with less competition may lead to more delays. Surprisingly, a less competitive route may reduce delays.
\end{abstract}

Key words: quality, airlines, travel time, delays, airline size

JEL codes: D22, L13, L93, R40 


\section{Introduction}

In 2016, over $24 \%$ of all US commercial flights were delayed. ${ }^{1}$ Delays are the most common sources of complaints from airline passengers (Dresner and $\mathrm{Xu}, 1995)$. There are several explanations for these delays. Airlines argue that they are innocent and mention extreme weather and bad air traffic control systems as causes. Policymakers argue that there are other reasons. Airlines overschedule and make use of overly small airplanes that require the same resources as large ones, but take fewer passengers (Ball et al., 2010). They also argue that the incentives to reduce the number of delays are too low on non-competitive routes and airports (Mazzeo, 2003). The costs of delays are enormous. Ball et al. (2010) estimated the total yearly cost of delays for the USA was 32 billion dollars. Half of these costs were borne by the consumer due to time lost by flight delays, cancellations and missed connections. Due to this, costumers also fly less, which also hurts airlines and airports.

The degree of airline competition on airports and air routes has decreased in recent decades. On average, there are now only two carriers on a route (Rupp et al., 2006). American, Southwest and Delta airlines are the three largest airlines in the USA. Together they had a market share of over 50\% of the domestic airline market in 2016 (see Section 3). Governments and consumer organisations have expressed concerns over the effect of the market concentrations and the increases in flight delays. One example that underlines this is a case against American Airlines. This airline was sentenced guilty of illegally maintaining a monopoly on the route from Dallas to Fort Worth Airport. United Airlines and US Air were close to a merger, but it was blocked by antitrust authorities after the charges were made against American Airlines (Mazzeo, 2003).

Mazzeo (2003), Rupp et al. (2006), Mayer and Sinai (2003) and Greenfield (2014) studied the relationship between flight delays and the level of competition on a route or airport, thereby testing theories about the effect of competition on service quality. Their findings suggest that less competition results in an inferior service quality. With the decreased competition in the airline industry, this is becoming a problem.

Previous research used the airline's market share on a route or at an airport. A novelty in our study is that we also consider the relationship between the total size of an airline and the quality of its flights. Nevertheless, we also control for the degree of competition on the route and at the airport. We expect to find opposing effects. On the one hand, given previous results, a larger market share on routes or airports will result in an inferior service quality due to lack of competition. Moreover, a large overall size and large name recognition may make it less necessary to invest in quality. On the other hand, a larger total size may improve the efficiency of the operational management and planning, thereby potentially reducing delays. Furthermore, a delayed flight is a bad signal for customers, so a larger airline may need to invest more in quality to prevent customers from disliking it. It is not clear which effects will

\footnotetext{
${ }^{1}$ See Section 3 for the datasource and calculations.
} 
dominate. Our results may be useful for policymakers to set standards and to control the quality of flights in the airline industry. They may also be interesting for airlines and provide them with insights on how to grow and provide high-quality services for the consumer.

We measure the total size of an airline by their total market share, the total amount of assets or the total number of full-time equivalent employees (FTE's). We use two measures of delays: delay time in minutes (corrected for weather delays) and a dummy variable that is one if a flight operates arrives over 15 minutes later than scheduled. Delays are the most common category of customer complaints (Dresner and Xu, 1995), and, consequently, both delay measures have been heavily used in the literature as measurements for the quality of airlines.

This paper analyses data for more than 4.8 million individual flights within the USA in 2016. The delay data comes from the on-time performance dataset of the U.S. Department of Transport. Other datasets of this department are used to measure airline size. The empirical analyses use linear regression models. Independent variables include total airline size, route market structure, airport market structure, distance, as well as characteristics of the airplane, flight and airport. For the month, day of the week and time of the day, we include dummy variables. We include fixed effects for the combination of origin and destination airport. Finally, we control for the weather by subtracting delays due to 'extreme weather' from the delay time; this results in sharper estimates without meaningfully affecting point estimates.

The remainder of the paper is structured as follows. Section 2 gives an in-depth discussion of the literature. Sections 3 and 4 describe the data and empirical set-up. Section 5 discusses the main regressions and numerous sensitivity analyses. Section 6 concludes.

\section{Literature Framework}

\subsection{Dimensions of Airline Quality}

Service quality of an airline is one of the most important criteria for costumers in choosing an airline (Truitt and Haynes, 1994). Gursoy et al. (2005) and Chen and Gayle (2013) argue that timeliness is an important attribute of quality. Chen and Gayle (2013) define timeliness in three dimensions. The first dimension is On-time performance, which they measured by delay time in minutes. The second dimension is Schedule delay, which is the gap between a passenger's preferred departure time and actual departure time. The third dimension is Total travel time, which is the time needed to bring a passenger from the origin airport to their destination airport.

In the widely used Airline Quality Rating from Bowen and Headley (2001), on-time performance is one of the criteria for determining airline quality. Moreover, other factors that are affected by delays are included in this rating: e.g., customer complaints and lost baggage. Mazzeo (2003), Rupp et al. (2006), Mayer and Sinai (2003), Greenfield (2014), Prince and Simon (2015), Gill and Kim (2016), Yimga (2016) and Elliott and Roach (1993) use dimensions of timeliness as measurement of quality. Total travel time is an important dimension of quality, just as delays are (Gursoy et al., 2005) 
We can conclude that timeliness is an important aspect of the quality of airlines, where ontime performance is the most commonly used and hence we will focus on it.

\subsection{On-Time Performance}

The U.S. Department of Transport defines a flight as delayed if it arrives more than 15 minutes later than scheduled in the Computerized Reservations Systems. ${ }^{2}$ Brueckner (2002), for instance, uses this definition. An advantage of this measure is its simplicity. Consumers like to arrive on schedule, and, hence, carriers use this measurement to increase their service quality. A disadvantage is that carriers may pad their flight schedule to reduce delays on paper (Mazzeo, 2003). Different modifications have been made by different authors. Mayer and Sinai (2003) created their own dependent variable of 'excess travel time', which is the difference between actual travel time of a flight and the minimum travel time on the route. By using this approach, the efficiency of the flight is estimated. Rupp et al. (2006) used the monthly percentage of flights arriving within 15 minutes of scheduled and the monthly average minutes late.

Bad weather causes and increases delays. In our 2016 dataset, extreme weather directly caused $0.51 \%$ of the delayed flights and $4.35 \%$ of the total delay time. The National Aviation Systems (NAS) caused $22.9 \%$ of total delay time. The NAS includes a broad set of conditions such as non-extreme weather, airport operations, heavy traffic and air traffic control. ${ }^{3}$ Nonextreme weather slows down a flight, but does not prevent flying. On average, $31.7 \%$ of the NAS delays were caused by weather. For example, Mazzeo (2003), Rupp et al. (2006), Mayer and Sinai (2003) and Greenfield (2014) considered weather delays, indicating the importance of taking it into account.

Congestion has been a large problem for airlines for a long time. Congestion can arise due to airport capacity constraints. For instance, if there are too few or too short runways, congestion can arise (Craig, 1988). Congestion varies over the hours of a day (Mayer and Sinai, 2002). This is partly because demand varies over the day (Borenstein and Netz, 1999), but also because congestion and delays build up over time. The frequency of flights differs during the year. Holidays days can explain why certain routes are busier than others in certain months. Congestion also varies over the months because the weather varies. The frequency of flying also differs over the days. Mazzeo (2003) confirms this by finding coefficients for months and days that are statistically different from each other. He argues that there may be strategic deployment of types of aircrafts and age of the aircrafts, and that this would influence delays. Therefore, it is important to consider the type and age of an aircraft used on a flight.

A hub airport is an airport where passengers can connect with other flights (Park, 1997). Rupp (2009) argues that on-time performance ratio is higher at hub airports. Passengers need

\footnotetext{
${ }^{2}$ Source: https://www.rita.dot.gov/bts/help_with_data/aviation/index.html accessed 28 July 2017.

${ }^{3}$ Source: https://www.transtats.bts.gov/OT_Delay/ot_delaycause1.asp?display=data\&pn=1 accessed 23 August 2017.
} 
to catch connecting flights, which will lead to high costs in cases of delays. Therefore, airlines try to reduce the delays of their flights operating from and to their hub airports (Morrison and Winston, 2007). Conversely, a hub airport needs to have arriving and departing flights that are close together in time, which increases congestion and means that delays multiply quickly. Hence, an airline that has a hub airport also imposes extra delays on its own and other airline's flights (Mayer and Sinai, 2002).

So, delays can be caused by bad weather, hubbing, congestion or variations in demand over the months or days. But they may also be caused by too much or too little competition.

\subsection{Competition and Quality: Previous Research}

This section will describe the previous research on the connection between competition and service quality.

Mazzeo (2003) investigated the effect of competition (market share) on service quality in the US airline industry. To determine the degree of competition, he used the market share of an individual airline at an airport. The data is from the United States Department of Transport. It has 800000 individual flights, including all flights scheduled between the 50 major airports in 2000. These airports were selected to include all of the major airline hubs, but also a few airports in smaller cities.

Mazzeo (2003) evaluated the on-time performance as a function of different variables. The first set of variables is about weather, including measures of rain, snow, fog, haze and thunderstorms. The second set of variables is about flight, airport and airplane characteristics. These variables also controlled for congestion at airports, which varies over the hour of a day (Mayer and Sinai, 2002). Mazzeo (2003) argues that there may be strategic deployment of certain types of aircrafts and age of the aircrafts. This would influence delays, and therefore he takes the type and age of an aircraft into account. The third set of variables controls for concentration effects. The variables include the airport market share, whether there is only one airline on a route, and the route HHI (Herfindahl-Hirschman index), which considers both direct trips and indirect trips via a hubbing airport. Independent variables include 'Minutes Late' and whether a flight is more than 15 minutes late. He concludes that airlines use their market power to impose lower quality through increased flight delays. If the airline does not face competition on routes or has a high market share at an airport, it can save costs by lowering quality. But the results are even more striking; it appears that airlines schedule longer flight times on their monopoly routes, all else being equal.

Rupp et al. (2006) investigated how route competition affects arrival delay time. They had a large dataset with twenty-seven-thousand monthly observations along 150 routes from 1997 to 2000. They used several measurements of competition on the routes: number of carriers, effective competitors, route market share, and a monopoly route indicator. They argue that the effect is the same for all their set-ups: competitive routes have slightly higher on-time arrival percentages (between 0.2 and 0.8 percentage points) and shorter average flight delays 
(between 0.3 and 0.7 minutes). But the effect of airport hubs is even better. Flights that originate from an airline's hub have between 3.0 and 3.3 percentage points lower average ontime arrival rates and between 1.2 to 1.4 minutes extra flight delay.

Mayer and Sinai (2003) used excess travel time (the difference between actual travel time and the minimum travel time on the route) as their delay measure. They considered all domestic flights by the major US airlines and use monthly data from 1988 to 2000. Network benefits due to hubbing and congestion externalities are the possible factors that explain the delays. They argued that increasing the connections to other airports due to hubbing creates new markets and thereby benefits for airlines and consumer. Delays could be just the counterpart of these benefits, as every hubbing flight creates congestion. They empirically found that congestion increases with hubbing activity at an airport and decreases with market concentration. Hub carriers cluster their flights in short time spans, making it possible for their passengers use many connections. In comparison, non-hub flights - operating at the same airport-fly with less delay time.

Yimga (2016) investigated the relationship between alliances and on-time performance. He found evidence that code-sharing alliances improve the on-time performance rate and allow for more efficient connections between flights. More efficient connections decrease the total travel time and thereby increase the quality of a flight. The effects depend on the pre-alliance situation on routes

Steven et al. (2016) considered airline mergers, and found that mergers directly increase frequency of delays but lower the occurrence of cancellations. However, mergers also increase route concentration (as measured by the $\mathrm{HHI}$ ), and this indirectly lowers the quality. Accordingly, this results in even more frequent delays and a net increase in cancellation.

Finally, Greenfield (2014) analysed delay occurrence as a function of market structure, airport traffic, weather, and exogenous demand and costs shifters. In contrast to previous research, market structure is an endogenous variable. He argued that ignoring this leads to endogeneity bias. As instruments for the market structure, he used the lagged market structure and airline mergers. He found there was a three-times-stronger effect of competition on airline delays than previous studies that treated the market structure as endogenous. He argued that this shows the importance of determining the market structure endogenously.

\section{Data}

We use several datasets from the U.S. Department of Transport. The first is the Airline OnTime Performance dataset from January 2016 until December 2016. ${ }^{4}$ It contains over 5.6 million flights for the 12 airlines that had to report delay data. For many flights, there is no information on delays. Consequently, the final dataset has 4.8 million observations. Our second datasource is the Schedule B-43 Inventory dataset on airplane characteristics. Finally,

\footnotetext{
${ }^{4}$ Source: https://www.transtats.bts.gov/Tables.asp?DB_ID=120\&DB_Name=Airline\%20On-

Time\%20Performance\%20Data\&DB_Short_Name=On-Time accessed 28 July 2017.
} 
we used two financial datasets, schedule P-1(a) and schedule B-1, ${ }^{5}$ for information on the total amount of assets and number of full time employees. ${ }^{6}$

For the size of an airline we use three measurements: (1) MARKET_SHARE is its total number of domestic flights as a percentage of all US domestic flights, (2) TOTAL_ASSESTS is its assets in billions of dollars, and (3) TOTAL_FTE is its total number of full-time equivalent employees (FTEs), normalised to be in groups of 10000 employees. We use two distinct measurements of delays. The first follows Chen and Gayle (2013) and is the minutes that a flight arrives delayed compared to its schedule. If a flight is on time or arrives earlier than scheduled, the delay is zero, as this is a good performance. For the second dependent, we follow the Department of Transport: a delay occurs if a flight arrives more than 15 minutes later than scheduled.

Table 1 shows that market share varies substantially between the 12 airlines, and the same holds for the percentage of flights delayed more than 15 minutes. The mean arrival delay is 11.9 minutes. Fig. 1 shows that most flights arrive early or on time, but $17.4 \%$ of the flights are late by 15 minutes or more.

Table 1. Code, airline, market share and flights delayed more than 15 minutes

\begin{tabular}{cccc}
\hline Code & Airline & $\begin{array}{c}\text { Market share } \\
\text { (\% total flights })\end{array}$ & $\begin{array}{c}\text { Delayed flights } \\
\text { (\% total flights airline) }\end{array}$ \\
\hline WN & Southwest Airlines & 23.13 & 37.35 \\
DL & Delta Airlines & 16.42 & 25.95 \\
AA & American Airlines & 16.28 & 36.71 \\
OO & SkyWest Airlines & 10.79 & 32.53 \\
UA & United Airlines & 9.70 & 29.31 \\
EV & ExpressJet Airlines & 8.74 & 31.88 \\
B6 & JetBlue Airlines & 5.03 & 39.06 \\
AS & Alaska Airlines & 3.15 & 31.05 \\
NK & Spirit Airlines & 2.46 & 40.56 \\
F9 & Frontier Airlines & 1.69 & 37.34 \\
HA & Hawaiian Airlines & 1.37 & 33.51 \\
VX & Virgin America & 1.23 & 43.04 \\
& & & \\
\hline
\end{tabular}

\footnotetext{
${ }^{5}$ Source: https://www.transtats.bts.gov/dataindex.asp?index=S\&listorder=TABLES accessed 28 July 2017.

${ }^{6}$ StataSE 14 was used for the calculations and regressions. The coding for calculations and estimations is available on request. The data can be found via the supplied URLs.
} 


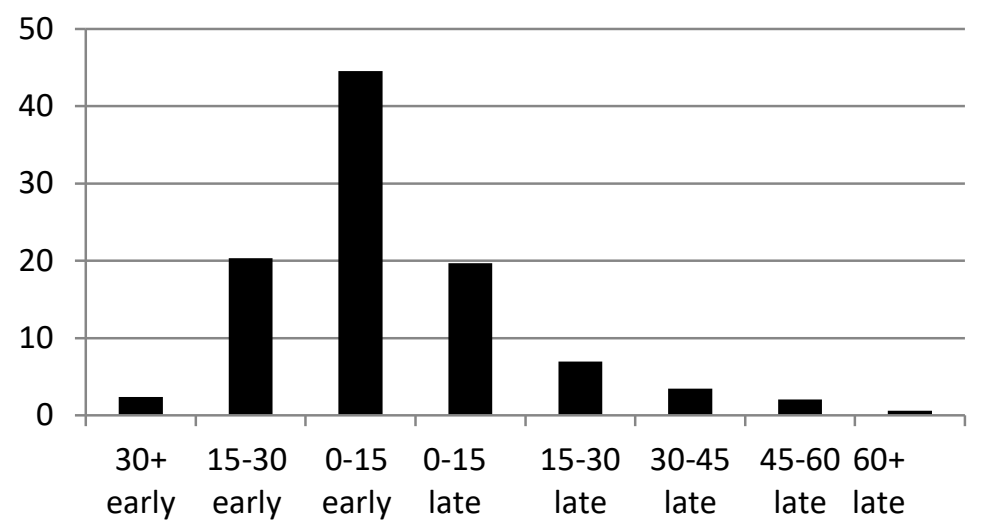

Fig. 1: Histogram of delay time (classified per 'early minutes' or 'late minutes' groups; percentages on the vertical axe)

Fig. 2 illustrates that on average, larger airlines are associated with shorter delays. However, to accurately investigate the effect of total market share on delays, we need to control for other factors, including: airport and market structure, weather, congestion, date, and characteristics of the airport, flight and airplane. All variables used are defined and summarised in Appendix 1. We will discuss the choice of these variables hereafter.

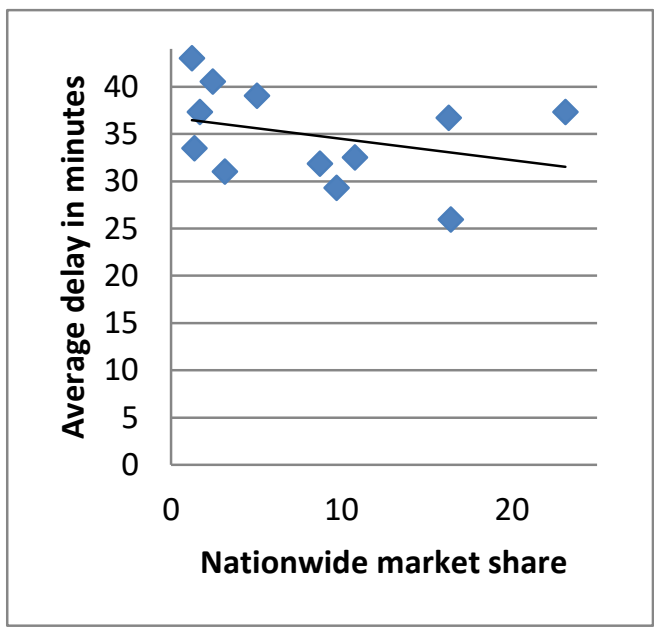

Fig. 2: Airline nationwide market share in 2016 vs. its average arrival delay in minutes

We want to disentangle the effect of the total airline size from the competition at the route and airport level. The first variable for this is HHI_ORIGIN. It equals the HerfindahlHirschman Index (HHI) based on the flights departing from an origin airport $o$ in month $m$ :

$$
\text { HHI_ORIGIN } \text { om }_{-}=\sum_{j=1}^{j=N_{\text {om }}}\left(\text { flight_ }_{-} \text {share }_{\text {jom }}\right)^{2} .
$$

Here, $N_{o m}$ is the number of airlines flying from airport $o$, and flight_share jom $_{\text {in }}$ is airline $j$ 's share of flights departing from $o$ in month $m$. The second variable HHI_DESTINATION is 
similarly defined using the flights arriving at the destination airport. Finally, SHARE_OD is the airline's share of direct flights in a month between the origin and destination airports. ${ }^{7}$

Weather has a large effect on delays. The dataset contains information on minutes delay due to extreme weather if the delay exceeds 15 minutes. To control for weather, we subtract extreme weather delay from the arrival delay to gain a corrected delay measure. ${ }^{8} \mathrm{We}$ will also control for the capacity of the plane used and its age. The older the airplane is, the larger the chance of technical problems. To allow for differences in delays over the months, day of the week and time of day, we include dummies on these.

Table 2. Airlines and their hub airports. ${ }^{9}$

\begin{tabular}{|c|c|}
\hline Airline & Hub airports \\
\hline Southwest Airlines & $\begin{array}{l}\text { Phoenix, Los Angeles, San Francisco, Denver, Orlando, Atlanta, Chicago, Baltimore- } \\
\text { Washington \& Las Vegas. }\end{array}$ \\
\hline Delta Airlines & $\begin{array}{l}\text { Los Angeles, Atlanta, O'Hare, Northern-Kentucky, Boston, Detroit, Minneapolis, New } \\
\text { York (LaGuardia and John F. Kennedy), Portland, Memphis, Dallas-Fort Worth, Salt } \\
\text { Lake City \& Seattle. }\end{array}$ \\
\hline American Airlines & $\begin{array}{l}\text { Phoenix, Los Angeles, Miami, O’Hare, Lambert-St. Louis, New York, Charlotte- } \\
\text { Douglas, Raleigh Durham, Philadelphia, Nashville, Dallas-Fort Worth \& Ronald } \\
\text { Reagan Washington. }\end{array}$ \\
\hline SkyWest Airlines & $\begin{array}{l}\text { O’Hare, Seattle, Portland, Los Angeles, San Francisco, Detroit, Minneapolis, Denver, } \\
\text { George Bush \& Phoenix. }\end{array}$ \\
\hline United Airlines & $\begin{array}{l}\text { Los Angeles, Detroit, Denver, O’Hare, Newark Liberty, Cleveland, Pittsburgh, George } \\
\text { Bush \& Washington Dulles. }\end{array}$ \\
\hline ExpressJet Airlines & Cleveland Hopkins, George Bush, Newark Liberty, O’Hare \& Seattle. \\
\hline JetBlue Airlines & Ft. Lauderdale-Hollywood, Boston \& Miami. \\
\hline Alaska Airlines & Ted Stevens Anchorage, Los Angeles, Portland \& Seattle-Tacoma. \\
\hline Spirit Airlines & Ft. Lauderdale-Hollywood, O'Hare \& Detroit. \\
\hline Frontier Airlines & Denver, O’Hare, Northern-Kentucky, Kansas, Trenton, Cleveland \& General Mitchell \\
\hline Hawaiian Airlines & Honolulu \& Kahului. \\
\hline Virgin America & Los Angeles \& San Francisco. \\
\hline
\end{tabular}

A hub is used by the Federal Aviation Administration to identify busy airports. An airport is a medium hub if it has between $0.25 \%$ and $1 \%$ of total US enplanements. A large hub has more than $1 \%$ of this total. Table 2 summarises the hubs. We allow that delays may be different if an airport is a medium or large hub via four airport-specific dummies: MEDIUM_HUB_ORIGIN, LARGE_HUB_ORIGIN, MEDIUM_HUB_ DEST and LARGE_HUB_DEST. We also allow that delays may be different if the flight is to or from an airline-specific hub via the airline and airport specific dummies: OUT_HUB_AIRPORT and IN_HUB_AIRPORT. Airlines may internalise more congestion at their own hubs since delays spread as passengers are delayed for their follow up flights. Conversely, a hub airport has many flights arriving and departing close together in time, implying more congestion for the

\footnotetext{
${ }^{7}$ It does not consider indirect hubbing connections, as the data is for individual flights and not for trips.

${ }^{8}$ For flights less than 15 minutes delayed, there is no information on extreme weather delays. To prevent many missing observations, we set the weather delay to zero, as extreme weather should cause long delays and indeed the average extreme weather delay is about 50 minutes.

${ }^{9} \mathrm{https} / / /$ www.faa.gov/airports/planning_capacity/passenger_allcargo_stats/passenger/media/cy15-commercial-serviceenplanements.pdf accessed 28 July 2017.
} 
same number of flights. These hub dummies allow for hub-related congestion. We also allow for congestion directly via the variables DEPARTURES_ORIGIN and ARRIVALS_DEST. The latter, for example, gives the monthly arriving flights at the destination.

Fixed effects are added for the combination of origin and destination airport. These control for airport capacity and other airport specific factors that cannot be measured directly. They also allow for route-specific effects between two airports. They may also prevent possible bias from reverse causality. An airline can fly between small airports with less congestion, which causes few delays and thereby gain a larger popularity and market share. However, a larger airline might also fly between high-demand cities with very congested airports. Without fixed effects, the market share variable could measure two effects: the effect of the airline size and the effect of congestion.

\section{Models and Hypotheses}

To predict the effect of the size of an airline on the quality, several regressions will be used. The first regression has as the dependent variable ARR_DELAY_CORR and has numerous control variables. The ARR_DELAY_CORR equals ARR_DELAY (= arrival delay time) minus WEATHER_DELAY, which is the delay time caused by extreme weather:

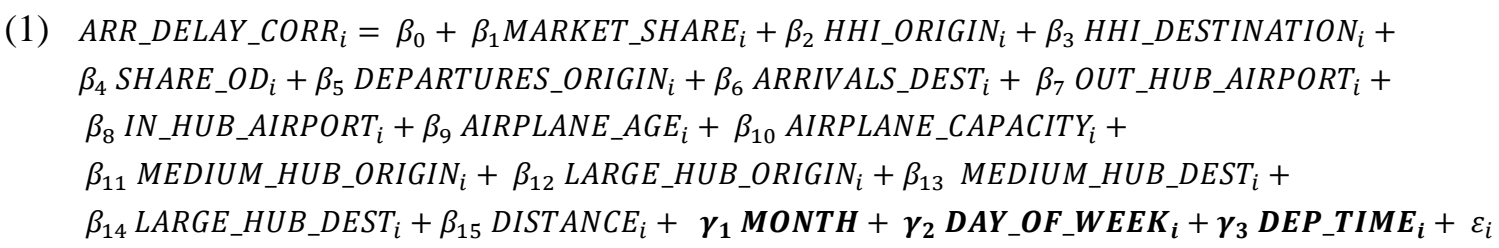

The variables in bold vector notation MONTH, DAY_OF_WEEK and DEP_TIME are vectors of dummies that control for time effects.

There are some airport-specific factors that are not considered in (1), such as airport capacity and demand for travel between two airports. Eq. (2) considers these by using a fixed effect on the combination of origin and destination airports. Hence, flights from Chicago O'Hare to Atlanta get a different fixed effect than those flying from Chicago to San Francisco. In total there will be 4492 fixed effects.
(2) ARR_DELAY_CORR ${ }_{i}=\beta_{0}+\beta_{1}$ MARKET_SHARE $_{i}+\beta_{2}$ HHI_ORIGIN $_{i}+\beta_{3}$ HHI_DESTINATION + $\beta_{4}$ SHARE_OD $_{i}+\beta_{5}$ DEPARTURES_ORIGIN ${ }_{i}+\beta_{6}$ ARRIVALS_DEST $i+\beta_{7}$ OUT_HUB_AIRPORT + $\beta_{8} I N_{-} H U B_{-} A I R P O R T_{i}+\beta_{9}$ AIRPLANE_AGE ${ }_{i}+\beta_{10}$ AIRPLANE_CAPACITY ${ }_{i}+\gamma_{1}$ MONTH + $\boldsymbol{\gamma}_{2}$ DAY_OF_WEEK $\boldsymbol{H}_{\boldsymbol{i}}+\boldsymbol{\gamma}_{3}$ DEP_TIME $_{\boldsymbol{i}}+$ FE_ OD ${ }_{i}+\varepsilon_{i}$

The distance is constant between OD pairs and the four airport-specific hub dummies are constant for an airport. Accordingly, in our fixed-effects estimations, these variables cannot be included and are controlled for by the fixed effects. 
Our second dependent variable is the dummy ARR_DELAY15, which is one if the flight arrives 15 minutes later than scheduled, and otherwise it is zero. A linear probability model will be estimated based on eq. (2): ${ }^{10}$

(3) ARR_DELAY15 $5_{i}=\beta_{0}+\beta_{1}$ MARKET_SHARE $_{i}+\beta_{2}$ HHI_ORIGIN $_{i}+\beta_{3}$ HHI_DESTINATION $_{i}+$ $\beta_{4}$ SHARE_OD $_{i}+\beta_{5}$ DEPARTURES_ORIGIN ${ }_{i}+\beta_{6}$ ARRIVALS_DEST ${ }_{i}+\beta_{7}$ OUT_HUB_AIRPORT ${ }_{i}+$

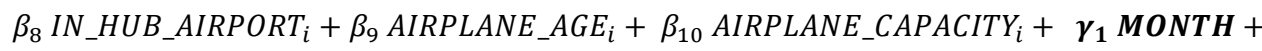
$\gamma_{2}$ DAY_OF_WEEK $_{i}+\gamma_{3}$ DEP_TIME $_{i}+F E_{-} O D_{i}+\varepsilon_{i}$

We will also use two other measurements of airline size as independent variables. So, we will also estimate eqs. (1)-(3) with TOTAL_ASSETS (total value of assets in billions of dollars) instead of MARKET_SHARE and with TOTAL_FTE (total full time employee equivalent).

Previous research on the connection between competition and service quality resulted in a negative correlation (Mayer and Sinai, 2003; Mazzeo, 2003; Rupp et al., 2006; Greenfield, 2014). We also consider the total size of an airline, and expect a positive relationship between the size of an airline and the average arrival delay. This is because of the efficiency gain that larger airlines can have. We also control for the market structure at the airport and route structure. Here, we expect that routes and airports with less competition have a lower quality as measured by the arrival delays.

\section{Empirical analysis}

\subsection{Results}

This section summarises the findings from the different models with the dependent variables ARR_DELAY_CORR and ARR_DELAY15. Table 2 shows the results when MARKET_SHARE measures the airline's total size. In all estimations, the standard errors were clustered on the combination of origin and destination airport, allowing for possible heteroscedasticity of the errors and serial correlation in the errors. Columns 2 and 3 also allow for 4492 fixed effects based on the combination of Origin and Destination (OD) pair airports, but it seems prudent to allow for possible remaining serial correlation. The fixed effects control for airport-specific factors and route-specific factors that are not measured directly in the model. ${ }^{11}$ In column 1 , which does not allow for fixed effects, there are strange results. It suggests that an airport with a higher HHI has fewer delays and that more departing flights leads to shorter delays. This indicates that not allowing for fixed effects leads to inconsistent estimates, and a Hausman test supports this. Therefore, we focus on the fixed effect estimations.

\footnotetext{
${ }^{10}$ Perhaps a probit model would be more appropriate, but our computational resources were not good enough to run a probit with such a large dataset.

${ }^{11}$ In the fixed effects estimations, we cannot include distance or the latter four hub dummies, as these are constant for each OD airport pair and their effects are thus captured by the fixed effects.
} 
In columns (2) and (3), we see that a larger nationwide market share of flights significantly lowers the delays in minutes and the chance of having a delay of more than 15 minutes (which is indicated by ARR_DELAY15=1 instead of 0). A share that is one percentage point higher leads to a 0.12 minutes lower delay. A larger HHI at the origin leads to longer delays and a larger chance of a delay. However, for the HHI at the destination the coefficient is not significant and the sign differs between columns (2) and (3). Surprisingly, a higher share of flights in a month between an origin and destination, i.e. a higher SHARE_OD, seems to lead to a shorter delay and a lower chance of delays. This would suggest that less competition on a route leads to shorter and fewer delays. As Chen and Gayle (2013) argue, more competition may force airlines to offer more quality in order to attract customers, but on a highly competitive route profits are always low and it may not be worthwhile to invest in quality. If so, airlines may accept a lower route share due to a low quality in order to have low costs.

Table 3: Main estimations of the effect of total airline size and market structure on delays

\begin{tabular}{|c|c|c|c|c|c|c|}
\hline & \multicolumn{2}{|c|}{ (1) ARR_DELAY_CORR } & \multicolumn{2}{|c|}{ (2) ARR_DELAY_CORR } & \multicolumn{2}{|c|}{ (3) ARR_DELAY15 } \\
\hline & coef. & t-stat & coef. & t-stat & coef. & t-stat \\
\hline MARKET_SHARE & $-0.14^{* * *}$ & -8.50 & $-0.12^{* * * *}$ & -8.37 & $-5.18 \mathrm{E}-04^{* *}$ & -2.38 \\
\hline HHI_ORIGIN & $-1.15^{*}$ & -2.90 & $5.64^{* *}$ & 3.37 & $0.048^{* *}$ & 2.46 \\
\hline HHI_DESTINATION & $-2.46^{* * *}$ & -6.46 & 0.93 & 0.77 & -0.0039 & -0.28 \\
\hline SHARE_OD & $-0.01^{* * *}$ & -3.49 & $-0.03^{* * *}$ & -8.85 & $-4.57 \mathrm{E}-04^{* * *}$ & -8.45 \\
\hline DEPARTURES_ORIGIN & $-2.88 \mathrm{E}-05^{*}$ & -2.01 & $2.03 \mathrm{E}-04^{* * *}$ & 3.49 & $2.28 \mathrm{E}-06^{* *}$ & 3.31 \\
\hline ARRIVALS_DEST & $1.05 \mathrm{E}-05$ & 0.71 & $1.45 \mathrm{E}-04^{* *}$ & 2.53 & $2.04 \mathrm{E}-06^{* *}$ & 2.72 \\
\hline DISTANCE & $-0.35^{* *}$ & -2.18 & & & & \\
\hline AIRPLANE_CAPACITY & $7.25 \mathrm{E}-06^{* * *}$ & 3.70 & 4.11E-06 & 1.85 & $-3.62 \mathrm{E}-08$ & -1.18 \\
\hline AIRPLANE_AGE & $0.074^{* * *}$ & 9.33 & $0.117^{* * *}$ & 20.82 & $0.0012^{* * *}$ & 14.54 \\
\hline OUT_HUB_AIRLINE & $-1.05^{* * *}$ & -4.03 & -0.39 & -1.45 & $-0.014^{* * *}$ & -3.79 \\
\hline IN_HUB_AIRLINE & $-1.47^{* * *}$ & -5.67 & $-1.31^{* * * *}$ & -4.96 & $-0.0076^{* *}$ & -2.00 \\
\hline MEDIUM_HUB_ORIGIN & $-0.80^{* *}$ & -2.55 & & & & \\
\hline MEDIUM_HUB_DEST & 0.51 & 1.74 & & & & \\
\hline LARGE_HUB_ORIGIN & 0.34 & 0.97 & & & & \\
\hline LARGE_HUB_DEST & $1.98^{* * *}$ & 5.70 & & & & \\
\hline MONTH dummies & \multicolumn{2}{|c|}{ YES } & \multicolumn{2}{|c|}{ YES } & \multicolumn{2}{|l|}{ YES } \\
\hline DEP_TIME dummies & \multicolumn{2}{|c|}{ YES } & \multicolumn{2}{|c|}{ YES } & \multicolumn{2}{|l|}{ YES } \\
\hline DAYS_OF_WEEK dummies & \multicolumn{2}{|c|}{ YES } & \multicolumn{2}{|c|}{ YES } & \multicolumn{2}{|l|}{ YES } \\
\hline Fixed effects on the OD pair & \multicolumn{2}{|c|}{$\mathrm{NO}$} & \multicolumn{2}{|c|}{4492} & \multicolumn{2}{|l|}{4492} \\
\hline Observations & \multicolumn{2}{|c|}{4798318} & \multicolumn{2}{|c|}{4798318} & \multicolumn{2}{|c|}{4798318} \\
\hline R-squared & \multicolumn{2}{|c|}{0.029} & \multicolumn{2}{|c|}{0.028} & \multicolumn{2}{|l|}{0.042} \\
\hline
\end{tabular}

Note: Significance levels are indicated: $* \mathrm{p}<0.05, * * \mathrm{p}<0.01$ and $* * * \mathrm{p}<0.001$. All standard errors were clustered on the combination of origin and destination airport. For the panel regressions with fixed effects on OD pair, the R-squared is the within $\mathrm{R}^{2}$ of the part of the variance of the demeaned data that is explained by the model. Coefficients of the dummies for DEP_TIME, DAYS_OF_WEEK and MONTH are available by request.

We included numerous controls. The coefficients of the monthly congestion variables DEPARTURES_ORIGIN and ARRIVALS_DEST show that in months with more aircraft 
movements, an individual flight has a longer expected delay and a higher chance of a delay (exceeding 15 minutes). If the origin or destination airport is an airline-specific hub, the arrival delay of this airline's flights will decrease compared to the flights of other airlines at this airport. This suggests that airlines may consider that the congestion they cause at hubs also delays their other hubbing flights, as was argued by Rupp (2009). In line with Pai (2010), a larger or older plane significantly increases delays. ${ }^{12}$

\subsection{Sensitivity analyses}

Now we investigate the sensitivity of our results to changes in the regression equation or variables. Tables A.2 and A.3 in the appendix use the variables TOTAL_ASSETS and TOTAL_FTE as alternative measures for total airline size. They show that arrival delay time significantly decreases with the total amount of assets in billions of US dollars and with the total employment. So the effect of total airline size seems robust to the way of measuring this size.

A very large percentage of flights have a zero delay or a negative delay that we set to zero. This may affect our results and could imply that standard FE regressions are not appropriate. To test this, we redid the analysis of eq. (2) in column 1 of Table A.4 for only the 1.6 million observations with a positive delay. This results in stronger effects of the nationwide market share as well as of the airport HHI and route share variables. The standard errors of these coefficients are also smaller.

Column (2) of Table A.4 redoes the estimation of eq. (2), but now without subtracting the weather delays. This is measured by the variable ARR_DELAY, which is the arrival delay in minutes with an arrival before scheduled defined as a zero delay. For column (3), we drop the observations with a zero delay under this alternative delay measure. The coefficients stay comparable, but the standard errors increase. This indicates that our correction for weather did not meaningfully affect point estimates, but it did sharpen them. ${ }^{13}$

The literature often uses logs of the dependent and independent variables. Estimating the model (2) using a log-log specification does not alter the results substantially. In column 1 of Table A.5, we use the log of ARR_DELAY_CORR. The number of observations drops, as the delay is often zero and you cannot take the $\log$ of zero. Therefore, in column 2 we use $\log ($ ARR_DELAY_CORR + 1) instead. Finally, column 3 uses the log of the delays without

\footnotetext{
${ }^{12}$ In column 1, the distance of a flight has a statistically negative effect on the delay time of a flight, as expected. However, an airline-specific hub may lower the delays for that airline, but it also affects other airlines. One airport-specific hub dummy is significantly negative, two are positive but insignificant and one is significantly positive. So the effect of a hub on delays seems ambiguous.

The coefficients for the months, day of the week and time of day are not shown in Table 2. Delays appear to be larger and more frequent in the summer and in December. Flights were also more likely to be delayed on Thursdays and Fridays. The average arrival delay seems the lowest for departures between 6 and 12 a.m. Later on in the day, especially between 6 p.m. and midnight, delays are longer. This is in contrast with Borenstein and Netz (1999), who argued that many flights leave at 8 a.m., which will probably create more congestion and may result in increasing departure delays. Our result may be because delays build up over the day, so that congestion at 8 a.m. also affects flights leaving at 3 a.m.

${ }^{13}$ If we were to delete a random selection of observations, we would also expect very minor changes in point estimates but increased standard errors.
} 
the weather delays subtracted. The effect of the airline size stays similar in all these specifications: a larger nationwide share of flights leads to significantly shorter delays. The effect of SHARE_OD also stays similar. However, the coefficient for HHI_ORIGIN is now insignificant and the sign switches between specifications.

As the effect for the airport market structure is not robust, we tried re-estimating the models without the HHI_ORIGIN and HHI_DESTINATION. We also tried also omitting the congestion variables and the SHARE_OD. The coefficient of the nationwide MARKET_SHARE was hardly affected.

We can conclude that the result for the effect of nationwide airline size is robust for transformations of the dependent variable, the independent variables and the specification: a nationwide larger share of flights leads to shorter and less frequent delays. The effects of the market structure at the airport level are much less robust, while again the effect of the share of flights at the route level seems robust.

\section{Conclusion and Discussion}

Air travel delays and on-time performance are the most common categories of customer complaints. Therefore, they are reasonable proxies for the service quality of a flight. We used two variables on delays: (1) delays in minutes later than scheduled and (2) if the delay was more than 15 minutes. We investigated the effect on these two quality measures of the total size of an airline. Nationwide airline size was measured in three different ways: the share of US domestic flights, total value of assets, and monthly employment. Controls were included for the market structure at the airport and route level, for congestion, for weather, for month, day and time of flying and for characteristics of the airport, flight and airplane.

A large amount of previous research has been done regarding the effect of competition and market share on service quality. The results generally show that less competition leads to a lower quality. These papers used the market share of an airline on a route or an airport, but did not consider the total size of an airline. We estimated numerous regressions that considered the effect of nationwide size as well as of competition at the airport and route.

Our results suggest that the larger the nationwide size of an airline is, the shorter and less frequent the delays. This result seems robust to the choice of specification, controls and variable set-up. Larger airlines have more resources, and the efficient use of these may decrease delays. For example, having many airplanes at different airports allows an airline to decrease arrival delay time, due to the use of stationed airplanes and equipment on these airports. If an airplane needs to be used several times a day, but is delayed, all the flights following it will be affected unless there is a replacement.

Previous research looked at the degree of competition at the route or airport. Our estimation found that if an airline has a larger share of flights on a route, then it has shorter and less frequent delays. This seems to contradict much of the previous research. Following 
Chen and Gayle (2003), more competition may force airlines to offer more quality if they want to attract customers. However, on a highly competitive route, profits are always low and it may not be worthwhile to invest in quality. The market situation at the airport also plays a role. Our main estimations implied that an origin airport with less competition has longer and more frequent delays. But here the results do not seem robust and are not always significant. To conclude, an increase in the total size of airlines decreases delays, but only if this increase is on competitive routes and airports.

It is important to evaluate the impact of airline size on quality. Ignoring this may lead to incorrect calculations of the impacts on welfare and profits from government policies and company behaviour. Our results indicate that policymakers and consumers need not worry about the influence of the nationwide size of an airline on delays; that is as long as there is enough competitiveness at airports. For airline mergers this suggests that their effect may not be detrimental for consumers. Although, as for example Steven et al, (2016) found, mergers also decrease the competition at the airport and route. Off course, prices and other forms of quality are not considered here. Other important dimensions of quality may be schedule delay, staff friendliness, baggage handling and food quality.

Our dataset has information on delay time caused by extreme weather, but only for flights delayed 15 minutes or more. Hence, no data is available for many of the flights. This may make our measurement of the dependent variable less reliable. For example, the direction of the wind influences the speed and turbulence of an airplane and therefore influences the delays. However, the influence of the missing information is not that strong, as the average extreme weather delay is about 50 minutes. We only considered competition at the airport and between direct flights between OD pairs. Although not directly possible with our dataset, it seems interesting to consider competition from indirect hubbing flights and from alternative airports.

\section{Acknowledgements}

We appreciate the comments of Mark Lijesen. Any remaining errors are ours. This research does not necessarily represent the views of our employers. 


\section{Appendix}

Table A.1: Variables, definitions and descriptive statistics

\begin{tabular}{|c|c|c|c|}
\hline Variable & Definition & Mean & $\begin{array}{l}\text { Std. } \\
\text { dev. }\end{array}$ \\
\hline \multicolumn{4}{|l|}{ Flights \& airports } \\
\hline DISTANCE & $\begin{array}{l}\text { Distance from origin to distance from origin to destination } \\
\text { airport, in } 1000 \text { miles }\end{array}$ & 0.85 & 0.62 \\
\hline OUT_HUB_AIRLINE & $\begin{array}{l}\text { Dummy Variable }=1 \text { if origin is a hub for the carrier of the } \\
\text { specific flight }\end{array}$ & 0.51 & 0.50 \\
\hline IN_HUB_AIRLINE & $\begin{array}{l}\text { Dummy Variable }=1 \text { if destination is a hub for the carrier of the } \\
\text { specific flight }\end{array}$ & 0.51 & 0.50 \\
\hline MEDIUM_HUB_ORIGIN & $\begin{array}{l}\text { Dummy variable }=1 \text { if enplanements of the origin airport is } \\
\text { between } 0.25 \% \text { and } 1 \% \text { of the total US number }\end{array}$ & 0.18 & 0.38 \\
\hline LARGE_HUB_ORIGIN & $\begin{array}{l}\text { Dummy variable }=1 \text { if enplanements of the origin airport is } \\
\text { above } 1 \%\end{array}$ & 0.68 & 0.47 \\
\hline MEDIUM_HUB_DEST & $\begin{array}{l}\text { Dummy variable }=1 \text { if enplanements of the destination airport is } \\
\text { between } 0.25 \% \text { and } 1 \% \text { of the total US number }\end{array}$ & 0.18 & 0.38 \\
\hline LARGE_HUB_DEST & $\begin{array}{l}\text { Dummy variable }=1 \text { if enplanements of the destination airport } \\
\text { above } 1 \% \text { of the total US enplanements }\end{array}$ & 0.68 & 0.47 \\
\hline DEPARTURES_ORIGIN & Number of departures from the origin airport in a month & & \\
\hline ARRIVALS_DEST & Number of arrivals to the destination airport in a month & & \\
\hline \multicolumn{4}{|l|}{ Airplane characteristics } \\
\hline AIRPLANE_AGE & Years since the manufacturing year & 12.85 & 7.08 \\
\hline AIRPLANE_CAPACITY & Capacity of airplane, in pounds & 59342 & 55312 \\
\hline \multicolumn{4}{|l|}{ Date characteristics } \\
\hline MONTH & Dummy variable for month is Jan, ..., December & & \\
\hline DAY_OF_WEEK & Dummy variable for day $=$ Monday, $\ldots$, Sunday & & \\
\hline DEP_TIME & $\begin{array}{l}\text { Dummy variable for if departure time is between } 00: 00-06: 00 \text {, } \\
06: 00-12: 00,12: 00-18: 00 \text { and 18:00-24:00 }\end{array}$ & & \\
\hline \multicolumn{4}{|l|}{ Airline size } \\
\hline MARKET_SHARE & $\begin{array}{l}\text { Amount of flight of an airline as percentage of total domestic } \\
\text { flights within the USA, in \% }\end{array}$ & 14.04 & 6.65 \\
\hline TOTAL_ASSETS & $\begin{array}{l}\text { Total assets of an airline for a certain month in billions of } \\
\text { dollars }\end{array}$ & 2.80 & 2.08 \\
\hline TOTAL_FTE & $\begin{array}{l}\text { Monthly average count of the Full-Time Employees in } 10000 \\
\text { persons (two half-time employees count as one full-time) }\end{array}$ & 5.23 & 3.46 \\
\hline \multicolumn{4}{|c|}{ 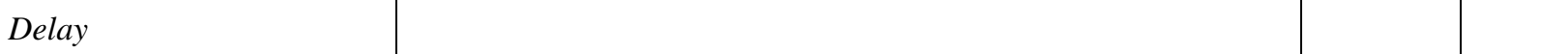 } \\
\hline ARR_DELAY & $\begin{array}{l}\text { Difference between arrival time in minutes and the scheduled } \\
\text { time; early arrivals have a zero delay }\end{array}$ & 11.85 & 38.36 \\
\hline WEATHER_DELAY & Delay time caused by extreme weather, in minutes & 2.70 & 21.39 \\
\hline ARR_DELAY_15 & $\begin{array}{l}\text { Dummy variable }=1 \text { if the flight arrives } 15 \text { minutes or more } \\
\text { later than the CRS arrival time. }\end{array}$ & 0.174 & 0.38 \\
\hline ARR_DELAY_CORR & ARR_DELAY minus WEATHER_DELAY, in minutes & 11.38 & 37.0 \\
\hline \multicolumn{4}{|l|}{ Market structure } \\
\hline HHI_ORIGIN & $\begin{array}{l}\text { Herfindahl-Hirschman Index based on the number of departures } \\
\text { from an origin airport in a month }\end{array}$ & 0.371 & 0.207 \\
\hline HHI_DESTINATION & $\begin{array}{l}\text { Herfindahl-Hirschman Index based on the number of arrivals at } \\
\text { a destination airport in the month of the observation }\end{array}$ & 0.371 & 0.207 \\
\hline SHARE_OD & $\begin{array}{l}\text { Share of the number of flights from an origin airport to a } \\
\text { destination airport for an airline in a month }\end{array}$ & 68.8 & 30.6 \\
\hline
\end{tabular}


Table A.2: Regressions on the delays with the total number of full time employees (TOTAL_FTE) as independent variable

\begin{tabular}{|c|c|c|c|c|c|c|}
\hline & \multicolumn{2}{|c|}{ (1) ARR_DELAY_CORR } & \multicolumn{2}{|c|}{ (2) ARR_DELAY_CORR } & \multicolumn{2}{|c|}{ (3) ARR_DELAY15 } \\
\hline & coef. & t-stat & coef. & t-stat & coef. & t-stat \\
\hline TOTAL_FTE & $-0.56^{* * *}$ & -19.0 & $-0.61^{* * *}$ & -22.1 & $-0.008^{* * * *}$ & -21.6 \\
\hline HHI_ORIGIN & $-1.47^{* * * *}$ & -3.81 & $4.58^{* *}$ & 2.84 & 0.031 & 1.64 \\
\hline HHI_DESTINATION & $-2.78^{* * *}$ & -7.60 & $-0.14^{*}$ & -0.12 & -0.021 & -1.51 \\
\hline SHARE_OD & -0.0032 & -1.14 & $-0.01^{* * *}$ & -3.54 & $-1.28 \mathrm{E}-04^{*}$ & -2.50 \\
\hline DEPARTURES_ORIGIN & $-8.16 \mathrm{E}-06$ & -0.58 & $2.20 \mathrm{E}-04^{* * *}$ & 3.79 & $2.54 \mathrm{E}-06^{* * *}$ & 3.70 \\
\hline ARRIVALS_DEST & $3.12 \mathrm{E}-05^{*}$ & 2.18 & $1.62 \mathrm{E}-04^{* *}$ & 2.84 & $2.31 \mathrm{E}-06^{* *}$ & 3.07 \\
\hline DISTANCE & -0.1 .8 & -1.13 & & & & \\
\hline AIRPLANE_CAPACITY & $1.65 \mathrm{E}-05^{* * *}$ & 9.60 & $1.45 \mathrm{E}-05^{* * * *}$ & 7.53 & 7.97E-08** & 3.00 \\
\hline AIRPLANE_AGE & $0.14^{* * *}$ & 16.6 & $0.17^{* * *}$ & 28.9 & $0.0020^{* * *}$ & 24.7 \\
\hline IN_HUB_AIRLINE & $-0.85^{* *}$ & -3.19 & 0.10 & -0.38 & -0.007 & -1.91 \\
\hline OUT_HUB_AIRLINE & $-1.26^{* * *}$ & -4.76 & $-1.00^{* * *}$ & -4.08 & $-1.27 \mathrm{E}-04$ & -0.04 \\
\hline MEDIUM_HUB_ORIGIN & -0.25 & -0.84 & & & & \\
\hline MEDIUM_HUB_DEST & $1.06^{* * *}$ & 3.88 & & & & \\
\hline LARGE_HUB_ORIGIN & $1.36^{* * *}$ & 3.86 & & & & \\
\hline LARGE_HUB_DEST & $3.00^{* * *}$ & 8.62 & & & & \\
\hline MONTH dummies & \multicolumn{2}{|c|}{ YES } & \multicolumn{2}{|c|}{ YES } & \multicolumn{2}{|c|}{ YES } \\
\hline DEP_TIME dummies & \multicolumn{2}{|c|}{ YES } & \multicolumn{2}{|c|}{ YES } & \multicolumn{2}{|c|}{ YES } \\
\hline DAYS_OF_WEEK dummies & \multicolumn{2}{|c|}{ YES } & \multicolumn{2}{|c|}{ YES } & \multicolumn{2}{|c|}{ YES } \\
\hline Fixed effects on the OD pair & \multicolumn{2}{|c|}{ NO } & \multicolumn{2}{|c|}{4492} & \multicolumn{2}{|c|}{4492} \\
\hline Observations & \multicolumn{2}{|c|}{4798318} & \multicolumn{2}{|c|}{4798318} & \multicolumn{2}{|c|}{4798318} \\
\hline R-squared & \multicolumn{2}{|c|}{0.029} & \multicolumn{2}{|c|}{0.029} & \multicolumn{2}{|c|}{0.043} \\
\hline
\end{tabular}

Note: TOTAL_FTE is in 10000 of Full time equivalence workers, so two half-time employees add up to one full time employee. All standard errors were clustered on the combination of origin and destination airport. Significance levels are indicated: * $\mathrm{p}<0.05, * * \mathrm{p}<0.01$ and ${ }^{* * *} \mathrm{p}<0.001$. For the panel regressions, the within $\mathrm{R}^{2}$ gives the part of the variance of the demeaned data that is explained by the model. Coefficients and t-statistics of the dummies for DEP_TIME, DAYS_OF_WEEK and MONTH are available by request. 
Table A.3: Regressions on the delays with the total amount of assets (TOTAL_ASSETS) as independent variable

\begin{tabular}{|c|c|c|c|c|c|c|}
\hline & \multicolumn{2}{|c|}{ (1) ARR_DELAY_CORR } & \multicolumn{2}{|c|}{ (2) ARR_DELAY_CORR } & \multicolumn{2}{|c|}{ (3) ARR_DELAY15 } \\
\hline & coef. & t-stat & coef. & t-stat & coef. & t-stat \\
\hline TOTAL_ASSETS & $-0.10^{* * *}$ & -22.1 & $-0.10^{* * * *}$ & -23.9 & $-0.002^{* * *}$ & -26.0 \\
\hline HHI_ORIGIN & $-1.57^{* * * *}$ & -4.1 & $4.54^{* *}$ & 2.80 & 0.029 & 1.50 \\
\hline HHI_DESTINATION & $-2.89^{* * *}$ & -7.98 & -0.18 & -0.15 & -0.023 & -1.70 \\
\hline SHARE_OD & -0.0039 & -1.41 & $-0.012^{* *}$ & -3.39 & $-8.03 \mathrm{E}-05$ & -1.68 \\
\hline DEPARTURES_ORIGIN & $-5.14 \mathrm{E}-07$ & -0.04 & $2.19 \mathrm{E}-04^{* * * *}$ & 3.78 & $2.56 \mathrm{E}-06^{* * *}$ & 3.73 \\
\hline ARRIVALS_DEST & $3.88 \mathrm{E}-05^{* *}$ & 2.75 & $1.61 \mathrm{E}-04^{* *}$ & 2.82 & $2.33 \mathrm{E}-06^{* *}$ & 3.09 \\
\hline DISTANCE & -0.07 & -0.48 & & & & \\
\hline AIRPLANE_CAPACITY & $1.38 \mathrm{E}-05^{* * *}$ & 8.16 & $1.23 \mathrm{E}-05^{* * *}$ & 6.34 & $5.72 \mathrm{E}-08^{*}$ & 2.17 \\
\hline AIRPLANE_AGE & $0.15^{* * *}$ & 18.3 & $0.17^{* * *}$ & 29.6 & $0.002^{* * *}$ & 26.5 \\
\hline IN_HUB_AIRLINE & $-0.80^{* *}$ & -3.08 & -0.13 & -0.51 & -0.007 & -1.90 \\
\hline OUT_HUB_AIRLINE & $-1.21^{* * *}$ & -4.67 & $-1.04^{* * *}$ & -4.21 & $2.60 \mathrm{E}-04$ & 0.07 \\
\hline MEDIUM_HUB_ORIGIN & -0.42 & -1.44 & & & & \\
\hline MEDIUM_HUB_DEST & $0.89^{* *}$ & 3.45 & & & & \\
\hline LARGE_HUB_ORIGIN & $1.30^{* * *}$ & 3.74 & & & & \\
\hline LARGE_HUB_DEST & $2.94^{* * *}$ & 8.68 & & & & \\
\hline MONTH dummies & \multicolumn{2}{|c|}{ YES } & \multicolumn{2}{|c|}{ YES } & \multicolumn{2}{|c|}{ YES } \\
\hline DEP_TIME dummies & \multicolumn{2}{|c|}{ YES } & \multicolumn{2}{|c|}{ YES } & \multicolumn{2}{|c|}{ YES } \\
\hline DAYS_OF_WEEK dummies & \multicolumn{2}{|c|}{ YES } & \multicolumn{2}{|c|}{ YES } & \multicolumn{2}{|c|}{ YES } \\
\hline Fixed effects on the OD pair & \multicolumn{2}{|c|}{ NO } & \multicolumn{2}{|c|}{4492} & \multicolumn{2}{|c|}{4492} \\
\hline Observations & \multicolumn{2}{|c|}{4798318} & \multicolumn{2}{|c|}{4798318} & \multicolumn{2}{|c|}{4798318} \\
\hline R-squared & \multicolumn{2}{|c|}{0.029} & \multicolumn{2}{|c|}{0.029} & \multicolumn{2}{|c|}{0.043} \\
\hline
\end{tabular}

Note: TOTAL_ASSETS is in billions of dollars in a month. All standard errors were clustered on the combination of origin and destination airport. Significance levels are indicated: $* \mathrm{p}<0.05$, ** $\mathrm{p}<0.01$ and $* * * \mathrm{p}<0.001$. For the panel regressions, the R-squared is the within $\mathrm{R}^{2}$ of the part of the variance of the demeaned data that is explained by the model. Coefficients and t-statistics of the dummies for DEP_TIME, DAYS_OF_WEEK and MONTH are available by request. 
Table A.4: Sensitivity analyses: excluding zero delays and excluding weather correction

\begin{tabular}{|c|c|c|c|c|c|c|}
\hline & \multicolumn{2}{|c|}{$\begin{array}{c}\text { (1)ARR_DELAY_CORR } \\
\text { if }>0\end{array}$} & \multicolumn{2}{|c|}{ (2) ARR_DELAY } & \multicolumn{2}{|c|}{$\begin{array}{l}\text { (3) } \text { ARR_DELAY_D_ }_{-} \\
\text {NEW if }>0\end{array}$} \\
\hline & coef. & t-stat & coef. & t-stat & coef. & t-stat \\
\hline MARKET_SHARE & -0.36 & -11.46 & -0.10 & -7.60 & -0.27 & -9.11 \\
\hline HHI_ORIGIN & 9.58 & 2.68 & 5.23 & 3.05 & 8.31 & 2.29 \\
\hline HHI_DESTINATION & 6.62 & 2.44 & 0.77 & 0.60 & 6.37 & 2.22 \\
\hline SHARE_OD & -0.03 & -3.76 & -3.29 & -8.86 & -0.03 & -3.85 \\
\hline DEPARTURES_ORIGIN & $-1.8 \mathrm{E}-05$ & -0.12 & $1.2 \mathrm{E}-04$ & 1.97 & $-2.6 \mathrm{E}-04$ & -1.65 \\
\hline ARRIVALS_DEST & $1.1 \mathrm{E}-04$ & 0.73 & $1.2 \mathrm{E}-04$ & 1.99 & $-5.6 \mathrm{E}-06$ & -0.03 \\
\hline AIRPLANE_AGE & 0.29 & 24.79 & 4.2E-06 & 1.91 & $3.0 \mathrm{E}-05$ & 11.72 \\
\hline AIRPLANE_CAPACITY & & & 0.12 & 20.93 & 0.28 & 24.17 \\
\hline IN_HUB_AIRLINE & 1.45 & 2.56 & -0.43 & -1.56 & 0.94 & 1.65 \\
\hline OUT_HUB_AIRLINE & -2.97 & -5.62 & -1.21 & -4.54 & -3.20 & -5.85 \\
\hline MONTH dummies & \multicolumn{2}{|c|}{ YES } & \multicolumn{2}{|c|}{ YES } & \multicolumn{2}{|c|}{ YES } \\
\hline DEP_TIME dummies & \multicolumn{2}{|c|}{ YES } & \multicolumn{2}{|c|}{ YES } & \multicolumn{2}{|c|}{ YES } \\
\hline DAYS_OF_WEEK dummies & \multicolumn{2}{|c|}{ YES } & \multicolumn{2}{|c|}{ YES } & \multicolumn{2}{|c|}{ YES } \\
\hline Fixed effects on the OD pair & \multicolumn{2}{|c|}{ YES } & \multicolumn{2}{|c|}{ YES } & \multicolumn{2}{|c|}{ YES } \\
\hline Observations & \multicolumn{2}{|c|}{1611280} & \multicolumn{2}{|c|}{4798318} & \multicolumn{2}{|c|}{1611280} \\
\hline R-squared & \multicolumn{2}{|c|}{0.04} & \multicolumn{2}{|c|}{0.03} & \multicolumn{2}{|c|}{0.03} \\
\hline
\end{tabular}

Note: Coefficients of the dummies for DEP_TIME, DAYS_OF_WEEK and MONTH are available by request. All standard errors were clustered on the OD-pair airports. The within $\mathrm{R}^{2}$ gives the part of the variance of the demeaned data that is explained by the model.

Table A.5: Regressions with the logs of the continuous variables

\begin{tabular}{|c|c|c|c|c|c|c|}
\hline & \multicolumn{2}{|c|}{$\begin{array}{c}\text { (1) LOG (ARR_DELAY } \\
\text { CORR) }\end{array}$} & \multicolumn{2}{|c|}{$\begin{array}{c}\text { (2) LOG (ARR_DELAY } \\
\text { CORR +1) }\end{array}$} & \multicolumn{2}{|c|}{$\begin{array}{l}\text { (3) LOG (ARR_ } \\
\text { DELAY) }\end{array}$} \\
\hline & coef. & t-stat & coef. & t-stat & coef. & t-stat \\
\hline LOG MARKET_SHARE & -0.05 & -6.70 & -0.05 & -6.63 & -0.04 & -5.91 \\
\hline LOG HHI_ORIGIN & 0.19 & 4.48 & 0.03 & 0.68 & -0.02 & -0.54 \\
\hline LOG HHI_DESTINATION & 0.07 & 1.92 & -0.09 & -2.74 & 0.02 & 0.47 \\
\hline LOG SHARE_OD & -0.06 & -7.11 & -0.05 & -7.00 & -0.04 & -6.49 \\
\hline LOG DEPARTURES_ORIGIN & 0.40 & 14.78 & -0.04 & -1.41 & -0.21 & -7.53 \\
\hline LOG ARRIVALS_DEST & 0.50 & 19.03 & 0.07 & 2.77 & -0.06 & -2.32 \\
\hline LOG AIRPLANE_CAPACITY & -0.05 & -5.83 & -0.05 & -5.43 & 0.06 & 11.72 \\
\hline LOG AIRPLANE_AGE & 0.04 & 14.35 & 0.04 & 14.18 & 0.06 & 27.13 \\
\hline IN_HUB_AIRLINE & -0.04 & -2.28 & -0.04 & -2.32 & -0.02 & -1.37 \\
\hline OUT_HUB_AIRLINE & 0.005 & -0.27 & -0.01 & -0.32 & -0.06 & -5.03 \\
\hline MONTH dummies & \multicolumn{2}{|c|}{ YES } & \multicolumn{2}{|c|}{ YES } & \multicolumn{2}{|c|}{ YES } \\
\hline DEP_TIME dummies & \multicolumn{2}{|c|}{ YES } & \multicolumn{2}{|c|}{ YES } & \multicolumn{2}{|c|}{ YES } \\
\hline DAYS_OF_WEEK dummies & \multicolumn{2}{|c|}{ YES } & \multicolumn{2}{|c|}{ YES } & \multicolumn{2}{|c|}{ YES } \\
\hline Fixed effects on the OD pair & \multicolumn{2}{|c|}{4492} & \multicolumn{2}{|c|}{4492} & \multicolumn{2}{|c|}{4492} \\
\hline Observations & \multicolumn{2}{|c|}{1611280} & \multicolumn{2}{|c|}{4798318} & \multicolumn{2}{|c|}{1611280} \\
\hline R-squared & \multicolumn{2}{|c|}{0.05} & \multicolumn{2}{|c|}{0.03} & \multicolumn{2}{|c|}{0.03} \\
\hline
\end{tabular}

Note: Coefficients of the dummies for DEP_TIME, DAYS_OF_WEEK and MONTH are available by request. All standard errors were clustered on the OD-pair airports. The within $\mathrm{R}^{2}$ gives the part of the variance of the demeaned data that is explained by the model. 


\section{References}

Borenstein, S., Netz, J., 1999. Why do all the flights leave at 8 am? Competition and departure-time differentiation in airline markets. International Journal of Industrial Organization, 17(5), 611-640.

Brueckner, J.K., 2002. Airport congestion when carriers have market power. American Economic Review, 92(5), 1357-1375.

Ball, M., Barnhart, C., Dresner, M., Hansen, M., Neels, K., Odoni, A., Peterson, E., Sherry, L., Trani, A., Zou, B., 2010. Total Delay Impact Study: A Comprehensive Assessment of the Costs and Impacts of Flight Delay in the United States. National Center of Excellence for Aviation Research: Berkeley. Accessed from https://www.researchgate.net/publication/272202358_Total_Delay_Impact_Study_A_Comprehensive_Assessment_of_th e_Costs_and_Impacts_of_Flight_Delay_in_the_United_States on 28 July 2017.

Bowen, B.D., Headley, D.E., 2001. Airline Quality Rating Report, paper 14. Accessed from Purdue e-Pubs at http://docs.lib.purdue.edu/aqrr/14 on 28 July 2017.

Chen, Y., Gayle, P., 2013. Mergers and product quality: Evidence from the airline industry. MPRA Paper No. 51238. Accessed from https://mpra.ub.uni-muenchen.de/51238/ on 3 June 2016.

Craig, T., 1988. Air Traffic Congestion: Problems and Prospects. National Research Council. Cities and their Vital Systems: Infrastructure Past, Present and Future. The National Academies Press, Washington, DC.

Dresner, M., Xu, K., 1995. Customer service, customer satisfaction, and corporate performance in the service sector. Journal of Business Logistics, 16(1), 24-40.

Elliott, K.M., Roach, D.W., 1993. Service quality in the airline industry: Are carriers getting an unbiased evaluation from consumers? Journal of Professional Services Marketing, 9, 71-82.

Gil, R., Kim, M., 2016. Does competition increase quality? Evidence from the US airline industry. SRRN working paper (version of 17 Jan 2016). Accessed from SSRN: http://dx.doi.org/10.2139/ssrn.2617528 on 3 June 2016.

Gursoy, D., Chen, M.H., Kim, H.J., 2005. The US airlines relative positioning based on attributes of service quality. Tourism Management, 26, 57-67.

Greenfield, D., 2014. Competition and service quality: New evidence from the airline industry. Economic of Transportation, $3,80-89$.

Mayer, C., Sinai, T., 2003. Network Effects, Congestion Externalities and Air Traffic Delays: Or Why Not All Delays are Evil. American Economic Review, 93(4), 1194-1215.

Mazzeo, M. J., 2003. Competition and service quality in the US airline industry. Review of industrial Organization, 22(4), 275-296.

Morrison, S., Winston, C., 2007. Another look at airport congestion pricing, American Economic Review, 97(5), 1970-1977.

Pai, V., 2010. On the factors that affect airline flight frequency and aircraft size. Journal of Air Transport Management, 16(4), $169-177$.

Park, J.H., 1997. Strategic airline alliance: Modelling and empirical analysis. PhD thesis, University of British Columbia. Accessed from https://open.library.ubc.ca/cIRcle/collections/ubctheses/831/items/1.0088337 on 28 July 2018.

Prince, J.T., Simon, D.H., 2015. The impact of mergers on quality provision: Evidence from the airline industry. Kelley School of Business Research Paper: No. 2014-03 (version of 9 Oct 2015). Accessed from http://dx.doi.org/10.2139/ssrn.2419611 on 6 June 2016.

Steven, A.B., Yazdi, A.A., Dresner, M., 2016. Mergers and service quality in the airline industry: A silver lining for air travelers? Transportation Research Part E, 89, 1-13.

Truitt, L.J., Haynes, R., 1994. Evaluating service quality and productivity in the regional airline industry. Transportation Journal, 33(4), 21--32.

Rupp, N., 2009. Do carriers internalize congestion costs? Empirical evidence on the internalization question. Journal of Urban Economics, 65, 24-37.

Rupp, N.G., Owens, D.H., Plumly, L.W., 2006. Does Competition Influence Airline On-Time Performance? In: D. Lee, (ed.), Advances in Airline Economics, Volume 1: Competition Policy and Antitrust, Elsevier, Amsterdam, pp. 251-272

Yimga, J.O., 2016. Airline code-sharing and its effects on on-time performance. Journal of Air Transport Management, 58, 76-90. 